Article

\title{
Preparation of Thin-Film Composite Nanofiltration Membranes Doped with N- and Cl-Functionalized Graphene Oxide for Water Desalination
}

\author{
Francisco J. García-Picazo ${ }^{1} \mathbb{D}$, Sergio Pérez-Sicairos ${ }^{1,2, *}$, Gustavo A. Fimbres-Weihs ${ }^{3} \mathbb{D}$, Shui W. Lin ${ }^{2}$, \\ Moisés I. Salazar-Gastélum ${ }^{1}$ and Balter Trujillo-Navarrete ${ }^{1}$
}

1 Departamento de Ingeniería Eléctrica y Electrónica, Tecnológico Nacional de México/Instituto Tecnológico de Tijuana, Tijuana, B.C. CP. 22500, Mexico; javier.garciap18@tectijuana.edu.mx (F.J.G.-P.); moises.salazar@tectijuana.edu.mx (M.I.S.-G.); balter.trujillo@tectijuana.edu.mx (B.T.-N.)

2 Centro de Graduados e Investigación en Química, Tecnológico Nacional de México/Instituto Tecnológico de Tijuana, Tijuana, B.C. CP. 22500, Mexico; shuiwhailin@tecijuana.edu.mx

3 School of Chemical and Biomolecular Engineering, The University of Sydney, Sydney, NSW 2006, Australia; gustavo.fimbresweihs@sydney.edu.au

* Correspondence: sperez@tectijuana.mx; Tel.: +52-664-623-4043

\section{check for}

updates

Citation: García-Picazo, F.J.; Pérez-Sicairos, S.; Fimbres-Weihs, G.A.; Lin, S.W.; Salazar-Gastélum, M.I.; Trujillo-Navarrete, B. Preparation of Thin-Film Composite Nanofiltration Membranes Doped with $\mathrm{N}$ - and Cl-Functionalized Graphene Oxide for Water Desalination. Polymers 2021, 13, 1637. https://doi.org/10.3390/polym13101637

Academic Editor: Tiziana Marino

Received: 11 March 2021

Accepted: 20 April 2021

Published: 18 May 2021

Publisher's Note: MDPI stays neutral with regard to jurisdictional claims in published maps and institutional affiliations.

Copyright: (c) 2021 by the authors. Licensee MDPI, Basel, Switzerland. This article is an open access article distributed under the terms and conditions of the Creative Commons Attribution (CC BY) license (https:// creativecommons.org/licenses/by/ $4.0 /)$.

\begin{abstract}
In the present work, chemically modified graphene oxide (GO) was incorporated as a crosslinking agent into thin-film composite (TFC) nanofiltration (NF) membranes for water desalination applications, which were prepared by the interfacial polymerization (IP) method, where the monomers were piperazine (PIP) and trimesoyl chloride (TMC). GO was functionalized with monomer-containing groups to promote covalent interactions with the polymeric film. The composite GO/polyamide (PA) was prepared by incorporating amine and acyl chloride groups into the structure of GO and then adding these chemical modified nanomaterial during IP. The effect of functionalized GO on membrane properties and performance was investigated. Chemical composition and surface morphology of the prepared GO and membranes were analyzed by thermogravimetric analysis (TGA), Raman spectroscopy, FTIR spectroscopy, X-ray photoelectron spectroscopy (XPS), X-ray diffraction (XRD), scanning electron microscopy (SEM), atomic force microscopy (AFM), and transmission electron microscopy (TEM). The fabricated composite membranes exhibited a significant increase in permeance (from 1.12 to $1.93 \mathrm{~L} \mathrm{~m}^{-2} \mathrm{~h}^{-1} \mathrm{bar}^{-1}$ ) and salt rejection for $\mathrm{Na}_{2} \mathrm{SO}_{4}$ (from 95.9 to $98.9 \%$ ) and $\mathrm{NaCl}$ (from 46.2 to $61.7 \%$ ) at 2000 ppm, when compared to non-modified membranes. The amine- and acyl chloride-functionalized GO showed improved dispersibility in the respective phase.
\end{abstract}

Keywords: graphene oxide; $\mathrm{N}$ - and Cl-functionalized graphene oxide; thin-film nanocomposite membrane; interfacial polymerization; nanofiltration

\section{Introduction}

Water covers almost 75\% of the earth's surface; nevertheless, it is expected that by 2025 half of the population will live in regions with water shortage [1]. Wastewater treatment and seawater desalination have been proposed to satisfy the increasing demand of this vital resource. Membrane separation processes emerged as a sustainable alternative to provide water to low rainfall areas [2]. Nanofiltration (NF) is a pressure-driven separation process with features similar to those of reverse osmosis (RO). These NF processes are able to partially reject small ions from water such as $\mathrm{NaCl}, \mathrm{Na}_{2} \mathrm{SO}_{4}, \mathrm{CaSO}_{4}$, and $\mathrm{CaCl}_{2}$; hence, it can be employed for water desalination $[3,4]$. Although NF membranes are very commercially successful, there are some major challenges to their performance such as the trade-off effect between salt rejection and water permeability [5-7], chlorine resistance [8], and fouling resistance [9].

$\mathrm{NF} / \mathrm{RO}$ membranes are typically fabricated by the interfacial polymerization (IP) method, which consists of a polycondensation reaction between two monomers occurring 
at the interface of two non-miscible solutions [10]. Typically, this process begins by wetting a polysulfone porous support with an aqueous amine solution and then applying an organic phase containing the acid chloride monomer; thereby, an ultrathin layer of polyamide (PA) is formed at the interface between the two phases and remains attached to the support [11-13]. This PA layer becomes the active layer of the NF membrane since it is exposed to the solutions during separation processes. Thus, many recent studies focus on modifying the PA layer structure [14]. IP enables the formation of a high-density polyamide layer on the support surface. In order to tune the properties of the polyamide layer, several factors may be controlled (e.g., an application method of the monomers [13], the thickness [15], the structure of the monomers [16], the number of layers [17,18], or the incorporation of nanomaterials in the matrix [19]).

Nanomaterials have attracted interest in recent years due to their labile properties. The embedding of nanoparticles into the polyamide layer may increase the hydrophilicity of the membrane and enhance salt rejection performance. Inorganic additives such as titanium dioxide [20-22], silica [23], silver [24], zinc oxide [25], and carbon nanotubes [26-29] have contributed to improving separation performance and increasing the fouling resistance of membranes. Recently, many investigations have studied the effect of the physical immobilization of graphene [30] and graphene oxide [31-33] into the polymeric matrix; however, the physical addition of GO in the PA layer produces disaggregation. One strategy is to functionalize GO in order to promote covalent bonding between GO and the polymeric film [34]. The introduction of monomers used during IP on the GO structure may increase the stability and crosslinking of the resulting composite film. The amine and acyl chloride groups may play a role as anchor-like sites for a PA layer to form. Nevertheless, the chemical immobilization of GO in the PA layer and the role of GO during IP have not been extensively discussed.

Graphene is a single layer of honeycomb-like atomic sp ${ }^{2}$ carbon atoms, while graphene oxide (GO) is a highly hydrophilic form of graphene containing bonded functional groups, such as carbonyl, hydroxyl, and epoxide, among others [35]. GO is mainly obtained by chemical exfoliation of bulk graphite using strong oxidant agents [36]. Adding this oxygenated nanomaterial may reduce the surface charge of membranes, thereby increasing electrostatic interactions between solutes and the surface of the membrane [37]. In addition, these aforementioned interactions between the membrane and solutes may reduce concentration polarization, increasing water flux [38]. Another highlight of GO is its capacity to generate (in the presence of water) reactive oxygen species (ROS), which are associated with bacterial growth inhibition, reducing biofouling of NF membranes [39]. These hydrophilic and antimicrobial properties of GO make its application on the polyamide layer very attractive for water flux enhancement. Despite these attributes, the low dispersibility of $\mathrm{GO}$ in the phases for interfacial polymerization remains inconvenient.

An innovative approach is to synthesize a functionalized GO monomer for the further incorporation during NF membrane preparation. The presence of amine and acyl chloride groups in GO may, in advance, improve dispersibility in the phases for membrane preparation and yield to covalent bonds between GO and monomers in solution, leading to a more dense film structure. Inducing these nitrogen- and chlorine-containing groups may increase the biofouling resistance of the NF membranes. A similar approach has been reported by Shao et al. [40] and Wen et al. [41].

The aim of this work is to study the effect of different functionalizations of GO on the properties of NF membranes. In this paper, the chemical modification of GO with amine and acyl chloride groups is reported. Both monomer-contained functionalized GO materials were incorporated into monomer solutions to obtain NF membranes, where GO could perform an active role during IP, modifying the characteristics and performance of NF membranes. To evaluate the possible participation of functionalized GO in IP, a reaction was carried out adding only a functionalized GO material and a monomer. The obtained NF membranes were characterized by several microscopic and spectroscopic techniques. The effect of the incorporation of modified GO on membrane performance was further 
studied. Additionally, the characterization and evaluation of the as-prepared membranes were performed.

\section{Experimental Section}

\subsection{Reagents}

Graphite powder (99.99\%), $\mathrm{H}_{2} \mathrm{SO}_{4}(98 \%)$, ethylenediamine (99\%), 1-[Bis(dimethylamino) methylene]-1H-1,2,3-triazolo[4,5-b]pyridinium 3-oxide hexafluoro-phosphate (HATU; 97\%), triphosgene (BTC; 98\%), carbon tetrachloride $\left(\mathrm{CCl}_{4} ; 99.9 \%\right)$, triethylamine $(99.0 \%), \mathrm{N}$-metil2-pirrolidone (NMP; 99.5\%), 2,2,4-trimethylpentane (iso-octane; 99.8\%), piperazine (PIP; $99 \%$ ), trimesoyl chloride (98\%), and $\mathrm{Na}_{2} \mathrm{SO}_{4}(99 \%)$ were provided from Sigma Aldrich (Saint Louis, $\mathrm{MO}, \mathrm{USA}) . \mathrm{H}_{3} \mathrm{PO}_{4}(86 \%), \mathrm{KMnO}_{4}(99 \%), \mathrm{H}_{2} \mathrm{O}_{2}(30 \%)$, and trichloromethane $(99.0 \%)$ were purchased from Fermont (Monterrey, Mexico). Ethanol (99.9\%) and $\mathrm{NaCl}(99.9 \%)$ were acquired from Fraga Lab (Mocorito Mexico). Polyvinyl alcohol (PVA; $513 \mathrm{~g} \mathrm{~mol}^{-1}$ ) was supplied by Celanese (Irving, TX, USA). Sucrose $\left([\alpha]_{D}^{25}\right.$ from $+66.3^{\circ}$ to $\left.+66.8^{\circ}\right)$, xylose $(98 \%)$, and raffinose pentahydrate $(98 \%)$ were purchased from Spectrum Chemical (New Brunswick, NJ, USA). Fructose (98\%) and $\mathrm{NaOH}(97 \%)$ were acquired from Jalmek Scientific (San Nicolas de los Garza, Mexico). Nitrogen gas (99.99\%) was purchased from Infra Gases (Naucalpan, Mexico). All reagents were used as received. The aqueous solutions were prepared with DI water (Merck, Milli-Q grade $18 \mathrm{M} \Omega$; Darmstadt, Germany).

\subsection{Analytical Techniques}

Raw and functionalized GO were analyzed by different analytical techniques: thermogravimetric analysis (TGA; TA Instruments, QA-600; New Castle, DE, USA) was carried out from $40-800{ }^{\circ} \mathrm{C}$ and $20^{\circ} \mathrm{C} \mathrm{min}^{-1}$; FTIR spectroscopy (Perkin Elmer, Spectrum 400; Waltham, MA, USA) was performed at a working range of $4000-600 \mathrm{~cm}^{-1}$, using ATR device, a resolution of $2 \mathrm{~cm}^{-1}$ and 16 scans; Raman spectroscopy (Thermo Scientific, Smart Raman DXR; Waltham, MA, USA) was performed using a range of $800-2200 \mathrm{~cm}^{-1}$ and a laser source of $780 \mathrm{~nm}$; X-ray Diffraction (XRD; Bruker, DaVinci; Billerica, MA, USA) was equipped with a source of $\mathrm{Cu}(\lambda=1.542 \AA)$ and a step size of $0.015^{\circ}$; XPS analysis $\left(\mathrm{SPECS}^{\circledR}\right.$ spectrometer with a PHOIBOS ${ }^{\circledR} 150$ WAL hemispherical energy analyzer) was carried out using an X-ray $\mathrm{Al}$ anode (monochromatized) at high intensity mode and a pressure below $1 \times 10^{-9}$ Torr, and high-resolution analysis was taken at a pass energy of $1 \mathrm{eV}$. XPS was also employed to ensure the chemical functionalization of GO. Deconvolution of the C 1s, N 1s, and $\mathrm{Cl} 2 \mathrm{p}$ peaks in XPS spectra was performed using a Gaussian multipeak fit in Origin 2018 software (version 95e). The $\mathrm{C}: \mathrm{O}$ atomic ratio was calculated as a ratio of peak intensity for each element. Transmission electron microscopy (TEM; JEOL JEM-2200FS; Akishima, Japan) in STEM mode at $200 \mathrm{kV}$ was performed in order to elucidate GO morphology. For each prepared GO, a selected micrograph was processed by fast Fourier transform (FFT) in ImageJ software (version 1.52a) to determine $d$-spacing. GO and membrane samples were imaged by SEM (Tescan, Vega 3; Brno, Czech Republic) operated at $20 \mathrm{kV}$, and a dried sample was placed on double-sided carbon tape. Atomic force microscopy (AFM; NanoSurf, EasyScan 2, Liestal, Switzerland) at contact mode and a scan rate of $1.0-2.0 \mathrm{kHz}$ was employed to determine the surface roughness of prepared membranes. Cross sectional samples were prepared via fracturing in liquid nitrogen and sputtered with $\mathrm{Ag}$ (SPI-Module, Sputter Coater; West Chester, PA, USA), and layer thickness was measured using ImageJ.

\subsection{Preparation and Functionalization of $G O$}

GO was prepared from graphite powder using the Marcano-Tour method with minor modifications [42]. Three grams of graphite was poured into $75 \mathrm{~mL}$ of a 9:1 mixture of concentrated $\mathrm{H}_{2} \mathrm{SO}_{4}$ and $\mathrm{H}_{3} \mathrm{PO}_{4}$ at $0{ }^{\circ} \mathrm{C}$ (cooling bath) and left under magnetic stirring for $30 \mathrm{~min}$. After that, $1 \mathrm{~g}$ of $\mathrm{KMnO}_{4}$ was added every $10 \mathrm{~min}$ until $6 \mathrm{~g}$ was reached. The mixture was kept under stirring at $0{ }^{\circ} \mathrm{C}$ for another $30 \mathrm{~min}$, and the cooling bath was then removed. When the mixture reached $35^{\circ} \mathrm{C}$, it was poured into $420 \mathrm{~mL}$ of DI water at $4{ }^{\circ} \mathrm{C}$ 
and then heated to $90{ }^{\circ} \mathrm{C}$ for $30 \mathrm{~min}$. Afterward, $9 \mathrm{~mL}$ of $\mathrm{H}_{2} \mathrm{O}_{2}$ was added into the mixture in order to remove any excess of unreacted $\mathrm{KMnO}_{4}$. At this point, the solution turned from dark violet to yellowish brown. The product was cooled to room temperature and left to sit for $8 \mathrm{~h}$. The supernatant was discarded, and the precipitate was rinsed thoroughly with DI water and centrifuged at $8000 \mathrm{rpm}$ for $10 \mathrm{~min}$. This last step was repeated until the $\mathrm{pH}$ of the rinse water reached a value of 6 . In order to remove any excess of moisture, the product was rinsed with acetone. The product was dried at $50{ }^{\circ} \mathrm{C}$ overnight and stored in vacuo. For $\mathrm{N}-\mathrm{GO}$ preparation, $400 \mathrm{mg}$ of GO was added to $40 \mathrm{~mL}$ of ethylenediamine and left under sonication for $20 \mathrm{~min}$ at $20^{\circ} \mathrm{C}$, followed by an addition of $4 \mathrm{mg}$ of HATU. The mixture

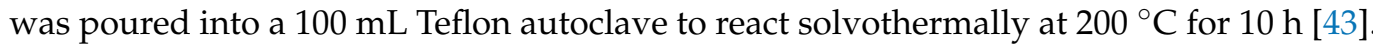
Once the reaction was completed, the precipitate was rinsed with DI water. The product was collected and dried at $50{ }^{\circ} \mathrm{C}$ overnight. To obtain $\mathrm{Cl}-\mathrm{GO}, 3 \mathrm{~g}$ of BTC was dissolved in $4 \mathrm{~mL}$ of $\mathrm{CCl}_{4}\left(\mathrm{BTC} / \mathrm{CCl}_{4}\right), 50 \mathrm{mg}$ of $\mathrm{GO}$ was dispersed in $3 \mathrm{~mL}$ of ethanol (GO/ethanol). Both $\mathrm{BTC} / \mathrm{CCl}_{4}$ and $\mathrm{GO} /$ ethanol were mixed in a $50 \mathrm{~mL}$ rounded-bottom flask under an ice bath and $\mathrm{N}_{2}$ protection. Once the mixture reached $0{ }^{\circ} \mathrm{C}$, a solution of $0.6 \mathrm{~mL}$ of triethylamine dissolved in $2 \mathrm{~mL}$ of $\mathrm{CCl}_{4}$ was added drop-wise until the cloudiness was completely dispersed. The mixture was kept under reflux at $65^{\circ} \mathrm{C}$ for $12 \mathrm{~h}[41,44]$. Once the reaction was completed, $40 \mathrm{~mL}$ of dry trichloromethane was added and the mixture was left to sit at room temperature. The supernatant was discarded and another four washes proceeded to eliminate any residual by-products from the mixture. All washes proceeded keeping $\mathrm{N}_{2}$ gas flow. The solid was finally dried running $\mathrm{N}_{2}$ gas and transferred to a tight seal container for further use.

To analyze the potential interactions of functionalized GO with the polyamide layer, an ex situ IP reaction was performed. For this, an aqueous dispersion of N-GO $0.004 \%$ was prepared and poured onto a small borosilicate plate, and a drop of a TMC solution at $1 \% w / v$ in iso-octane was then added on top of the plate. Then, we performed a reaction by wetting a borosilicate plate with an aqueous solution of $0.25 \% \mathrm{w} / \mathrm{v}$ PIP and adding a dispersion of $\mathrm{Cl}-\mathrm{GO} 0.004 \% w / v$ in iso-octane. A control IP reaction was set using PIP and TMC as monomers in the aqueous and organic solutions, respectively. The purpose of this test was to prove the interactions between N-GO and Cl-GO with the complementary monomer; therefore, it was performed in an isolated environment to eliminate the interference from the PSf substrate.

\subsection{Fabrication of GO/PA Nanocomposite Membranes}

The polysulfone (PSf) support membrane was prepared by casting a solution of $20 \%$ $w / w$ PSf in NMP onto a non-woven fabric (AWA \#16) using a knife gap of $170 \mu \mathrm{m}$ at room temperature. The cast film was immersed into a coagulation water bath for $10 \mathrm{~min}$. The prepared support was rinsed thoroughly using DI water and stored in a water bath at $4{ }^{\circ} \mathrm{C}$. TFC NF membranes were prepared through the IP method. The aqueous phase $(0.25 \%$ PIP, $0.50 \% \mathrm{NaOH}$ and $0.25 \%$ PVA) was applied onto PSf support membrane using a soft paintbrush, and any excess was then removed with a rubber roller. Next, organic phase (TMC $1 \% w / v$ in dry iso-octane) was poured over an aqueous phase and allowed to react for $30 \mathrm{~s}$. The IP reaction was then stopped by drying with nitrogen gas at $20 \mathrm{~L} \mathrm{~min}^{-1}$ and 3.5 bar for $1 \mathrm{~min}$ and then cured at $70^{\circ} \mathrm{C}$ for $10 \mathrm{~min}$. Control membrane obtained by IP was labeled as NF1. Next, five different membranes were prepared including nanomaterial (NF2-NF6). Raw GO at $0.004 \% w / v$ was added to NF2 and NF4 in the aqueous and organic phases, respectively. NF3 contains $0.004 \% w / v$ of N-GO in the aqueous phase and NF5 contains Cl-GO $0.004 \% w / v$ in the organic phase. Lastly, NF6 was prepared by adding $0.002 \% w / v$ of N-GO and $0.002 \% w / v$ of $\mathrm{Cl}-\mathrm{GO}$ into the aqueous and organic phases, respectively. Solution composition for preparation of NF membranes is presented in Table 1. 
Table 1. Reagents concentrations in aqueous and organic phases for the prepared membranes (percentage is expressed as $w / v$ ).

\begin{tabular}{cccccccc}
\hline & Reagent & NF1 & NF2 & NF3 & NF4 & NF5 & NF6 \\
\hline \multirow{5}{*}{ Aqueous phase } & PIP & $0.25 \%$ & $0.25 \%$ & $0.25 \%$ & $0.25 \%$ & $0.25 \%$ & $0.25 \%$ \\
& NaOH & $0.50 \%$ & $0.50 \%$ & $0.50 \%$ & $0.50 \%$ & $0.50 \%$ & $0.50 \%$ \\
& PVA & $0.25 \%$ & $0.25 \%$ & $0.25 \%$ & $0.25 \%$ & $0.25 \%$ & $0.25 \%$ \\
& GO & - & $0.004 \%$ & - & - & - & - \\
& N-GO & - & - & $0.004 \%$ & - & - & $0.002 \%$ \\
\hline \multirow{5}{*}{ Organic phase } & TMC & $1.00 \%$ & $1.00 \%$ & $1.00 \%$ & $1.00 \%$ & $1.00 \%$ & $1.00 \%$ \\
& GO & - & - & - & $0.004 \%$ & - & - \\
& Cl-GO & - & - & - & - & $0.004 \%$ & $0.002 \%$ \\
\hline
\end{tabular}

\subsection{Performance of NF Membranes}

All tests (salt rejection, water flux, and molecular weight cut-off (MWCO)) were evaluated in a cross-flow system as described by Lin et al. [45]. The transmembrane pressure was fixed to 5.5 bar, the effective surface area in the cell was $22.5 \mathrm{~cm}^{2}$, and the temperature was set to $25 \pm 2{ }^{\circ} \mathrm{C}$. Salt rejection tests were performed using solutions containing either $2000 \mathrm{mg} \mathrm{L}^{-1} \mathrm{Na}_{2} \mathrm{SO}_{4}$ or $2000 \mathrm{mg} \mathrm{L}^{-1} \mathrm{NaCl}$, while the water flux test was conducted with DI water. Permeate solutions were collected until $10 \mathrm{~mL}$ was obtained, and the time was recorded. All measurements were taken twice, and the average value was calculated. Equation (1) was used to determine the permeance ( $\Pi)$ for the membranes $\left(\mathrm{L} \mathrm{m}^{-2} \mathrm{bar}^{-1} \mathrm{~h}^{-1}\right)$ :

$$
\Pi=\frac{V}{A \times P \times t}
$$

where $V$ is the volume of permeate $(\mathrm{L}), A$ is the effective area of the membrane $\left(\mathrm{m}^{2}\right), P$ is the operating pressure (bar), and $t$ is the permeation time (h).

The solute rejection $\left(R_{S}, \%\right)$ was computed for each of the membranes according to Equation (2):

$$
R_{S}(\%)=\left(1-\frac{C_{p}}{C_{f}}\right) \times 100
$$

where $C_{p}$ is the concentration of solute in the permeate solution, and $C_{f}$ is the concentration of solute in the feed solution. For salt rejection tests, salt concentration was determined by measuring the conductivity of the solutions. To determine the MWCO for the prepared membranes, neutral solute rejection tests were carried out using four different saccharide solutions at $1 \% w / v$ : xylose, fructose, sucrose, and raffinose with molecular weights of $150.13,180.2,342.3$, and $504.5 \mathrm{~g} \mathrm{~mol}^{-1}$, respectively. The concentration of saccharides in the permeate solution was determined by measuring the total organic carbon (TOC; ThermoScientific, HiperTOC analyzer; Waltham, MA, USA). The MWCO was estimated assuming that the membrane pore size distribution behaves log-normally and the fraction of the solute that permeates across the membrane $(\theta)$ is proportional to the fraction of the membrane pores that are permeable to that solute. This value depends on the StokesEinstein radius $(a)$. All pores with a pore size greater than $a$ will be permeable to the solute. Thereby, $\theta(a)$ is the area under the normalized probability density function (NPDF) of the pore size distribution [46]. $\theta(z)$ is then given by Equation (3).

$$
\theta(z)=\int_{z}^{\infty} \frac{1}{\sqrt{2 \pi}} \exp \left(-\frac{z^{2}}{2}\right) d z=\frac{1}{2} \operatorname{erfc}\left(\frac{z}{\sqrt{2}}\right)
$$

where $z$ is parameterized according to Equation (4):

$$
z=\frac{\log (a / \bar{a})}{\log \sigma_{a}}
$$


Here, $a$ is the Stokes radius of the solute, $\bar{a}$ is the geometric mean radius of the pores, and $\sigma_{a}$ is the geometric standard deviation of the pore sizes. By inverting Equation (3) and using Equation (4), we can obtain Equation (5):

$$
\log a=\log \bar{a}+\sqrt{2} \log \sigma_{a} \operatorname{erfc}^{-1}[2 \theta(z)]
$$

The previous parameter can be evaluated by plotting Equation (5).

The Stokes radius can be estimated as a function of the molecular weight $(M W)$ by using Equation (6) [47,48]:

$$
\log a=-1.52517+0.47956 \log M W
$$

\section{Results and Discussion}

\subsection{Characterization of Functionalized GO}

Results for the physicochemical characterization of synthesized and functionalized GO materials are shown in Figure 1. Firstly, the synthesized GO nanostructures were characterized by FTIR spectroscopy (Figure 1a). The FTIR spectra of pristine GO show intense peaks at 3200-3500, 1699, and $1563 \mathrm{~cm}^{-1}$ due to $\mathrm{O}-\mathrm{H}, \mathrm{C}=\mathrm{O}$ stretching, and $\mathrm{C}=\mathrm{C}$ stretching vibrations, respectively [49]. For N-GO, the carboxyl vibration signal is not present, suggesting that, in this case, amine groups displaced the - $\mathrm{OH}$ group. Additionally, the $\mathrm{C}=\mathrm{O}$ stretching peak at $1699 \mathrm{~cm}^{-1}$ is no longer present; instead, two peaks appear at 1630 and $1540 \mathrm{~cm}^{-1}$, which are related to amide-I and amide-II bands, respectively [40]. Moreover, the weak signal at $1148 \mathrm{~cm}^{-1}$ may be related to the $\mathrm{C}-\mathrm{N}$ bond stretching. The absence of signals for N-H stretching (3500-3700 $\mathrm{cm}^{-1}$ ) may indicate a significant proportion of tertiary amide groups, suggesting that a single ethylenediamine chain may react at different locations in the GO structure. The appearance of signals at 1170, 1000, and $720 \mathrm{~cm}^{-1}$ in the FTIR spectra of Cl-GO may be related to C-Cl stretching and asymmetric stretching from carbonyl halide groups [50]. Additionally, the carbonyl peak suffered a slight displacement to a higher wavenumber from 1699 to $1717 \mathrm{~cm}^{-1}$, which suggests the presence of acyl chloride functional groups. This last spectrum also shows multiple peaks at 2980, 2600, and $2495 \mathrm{~cm}^{-1}$, which may be associated with ammonium salts formed as a byproduct during the synthesis procedure.

The Raman spectrum of prepared GO (Figure 1 b) shows a D peak $\left(1340 \mathrm{~cm}^{-1}\right)$ and a G peak $\left(1590 \mathrm{~cm}^{-1}\right)$; the former peak is associated with carbon lattice distortion, and the latter peak with $\mathrm{sp}^{2}$ hybridization of graphitic carbon. A high increase in defect/graphitic band relation (i.e., $\mathrm{I}_{\mathrm{D}} / \mathrm{I}_{\mathrm{G}}$ ratio) for $\mathrm{N}-\mathrm{GO}$ and $\mathrm{Cl}-\mathrm{GO}$ can be observed, when compared to pristine GO. Solvothermal treatment may have induced major structure defects on GO, mostly in $\mathrm{C}=\mathrm{C}$ bonds, causing the $\mathrm{I}_{\mathrm{D}} / \mathrm{I}_{\mathrm{G}}$ ratio to increase. Additionally, $\mathrm{N}$ and $\mathrm{Cl}$ may have been incorporated into the GO structure generating a larger amount of defects.

Thermogram curves of the synthesized materials are presented in Figure 1c. Three major weight losses can be observed for pristine GO. Weight losses at lower temperatures are associated with labile functional groups such as carboxylic acids, so a high degree of functionalization of GO (30\%) was obtained. For N-GO, these drops were significantly reduced due to functional group displacement. A drop at $350{ }^{\circ} \mathrm{C}$ was present for N-GO instead of at $240{ }^{\circ} \mathrm{C}$ for pristine GO, suggesting the successful introduction of more stable functional groups in the GO structure. The increase in thermal stability of N-GO could be related to the presence of amino-carbons and to a partial reduction of $\mathrm{GO}$, as reported by Irani et al. [43]. Cl-GO exhibited a mass drop of $40 \%$ at $170-200{ }^{\circ} \mathrm{C}$, which may correspond to acyl chloride groups. This shift to lower temperature may be attributed to the presence of highly labile functional groups in Cl-GO. In accordance with these results, the proposed order for thermal stability of functional groups is $\mathrm{NH}_{2}>\mathrm{COOH}>\mathrm{COCl}$. 

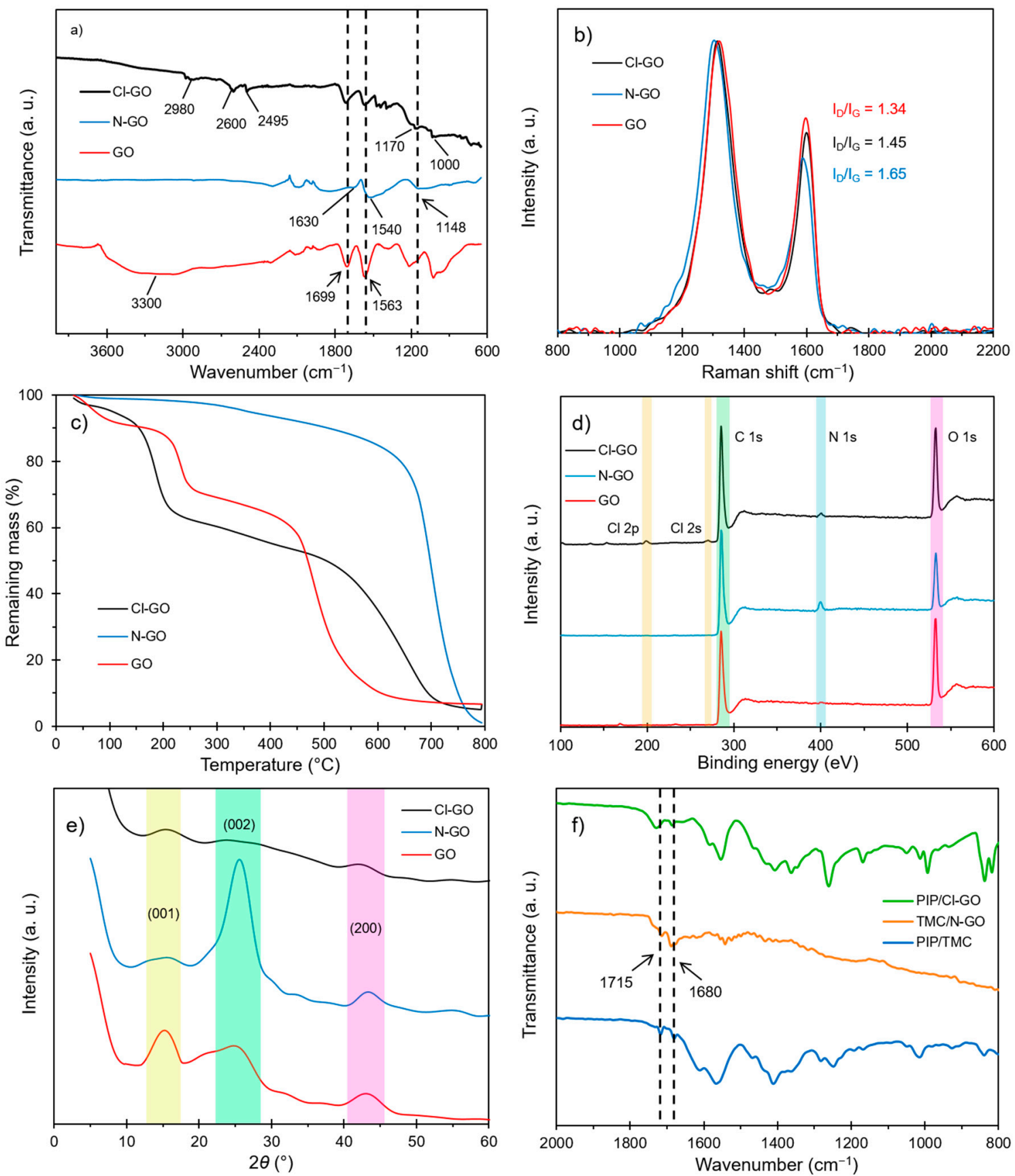

Figure 1. Physicochemical characterization of synthesized GO: (a) FTIR spectra, (b) Raman spectra, (c) TGA curves, (d) full XPS spectra, (e) XRD diffractograms, and (f) FTIR spectra of the ex situ IP reaction.

To ensure the attachment of nitrogen- and chlorine-containing functional groups, the chemical composition of prepared GO was analyzed via XPS. As shown in Figure 1d, for pristine GO, only two peaks can be observed, and they are attributed to $\mathrm{C} 1 \mathrm{~s}(\sim 288 \mathrm{eV})$ and $\mathrm{O} 1 \mathrm{~s}(\sim 533 \mathrm{eV})$ photoelectron lines. N-GO spectra showed a peak at $\sim 400 \mathrm{eV}$, confirming the presence of $\mathrm{N} 1 \mathrm{~s}$ [51]. The $\mathrm{C}: \mathrm{O}$ atomic ratio increased from 0.883 for pristine $\mathrm{GO}$ to 1.264 for $\mathrm{N}-\mathrm{GO}$, confirming the de-oxygenation of GO and the introduction of nitrogen. Additionally, XPS spectra of Cl-GO showed two low intensity peaks at $198.5 \mathrm{eV}$ and $271 \mathrm{eV}$ corresponding to $\mathrm{Cl} 2 \mathrm{p}_{3 / 2}$ and $\mathrm{Cl} 2 \mathrm{~s}$ photoelectron lines, respectively [52]. The shift to lower binding energy of $\mathrm{Cl} 2 \mathrm{p}_{3 / 2}$ transition to $198.5 \mathrm{eV}$ suggests the presence of an alkyl halide in $\mathrm{Cl}-\mathrm{GO}$ [53]. Likely, $\mathrm{Cl}$ displaced $\mathrm{O}$ in the $\mathrm{GO}$ structure due to a significant increase of the C:O atomic ratio to 1.013. In agreement with the FTIR analysis, the XPS spectrum 
of Cl-GO shows a low intensity peak at $402 \mathrm{eV}$, indicating the presence of some residual nitrogen ( $\mathrm{N} 1 \mathrm{~s}$ ); nevertheless, the displacement to higher binding energy suggests that $\mathrm{N}$ may have formed ammonium salts, which do not participate in IP [53]. For each material, C 1 s peaks were deconvolved into three different peaks at 285, 286.5, and $288 \mathrm{eV}$, identified as $\mathrm{C} 1, \mathrm{C} 2$, and $\mathrm{C} 3$, respectively. $\mathrm{C} 1$ corresponded to $\mathrm{C}$ bonded with $\mathrm{C}$ and $\mathrm{H}, \mathrm{C} 2$ corresponded to $\mathrm{C}$ bonded to electron withdrawing atoms such as $\mathrm{O}$ and $\mathrm{Cl}$, and $\mathrm{C} 3$ was associated with $\mathrm{C}=\mathrm{O}$ [53]. Deconvolution of the $\mathrm{N} 1$ s peak into N1 $(399.5 \mathrm{eV})$ and N2 (402 eV) was performed for $\mathrm{N}-\mathrm{GO}$ and $\mathrm{Cl}-\mathrm{GO}$. N1 was associated with $\mathrm{N}$ bonded to $\mathrm{C}$ and $\mathrm{H}$, and $\mathrm{N} 2$ was related to $\mathrm{N}$ bonded to electron withdrawing atoms $(\mathrm{O}$ and $\mathrm{Cl}$ ) or to $\mathrm{N}$ from ammonium salts. From the chemical environment of N bonding, only N1 may participate during IP. An N2 peak was also obtained in order to detect any residual nitrogen in Cl-GO.

Results of the deconvolution for each peak are presented in Table 2 as a fraction of the total amount of the element. It is shown that $\sim 80 \%$ of $\mathrm{N}$ in N-GO corresponded to N1, which may form covalent interactions with PA. Most of the residual $\mathrm{N}$ in $\mathrm{Cl}-\mathrm{GO}$ belongs to the N2 type, which may not participate in IP.

Table 2. Relative ratio (\%) of atomic species obtained by deconvolution of XPS spectra.

\begin{tabular}{cccccc}
\hline Sample & C1 & C2 & C3 & N1 & N2 \\
\hline GO & 69.7 & 5.2 & 25.1 & N/D & N/D \\
\hline N-GO & 62.4 & 16.8 & 20.8 & 78.0 & 20.0 \\
\hline Cl-GO & 68.7 & 9.8 & 21.5 & 24.5 & 75.5 \\
\hline
\end{tabular}

The crystalline structure of GO-based materials was studied by XRD (Figure 1e). The diffraction pattern of pristine GO showed a characteristic peak at $2 \theta=14^{\circ}$, associated with the diffraction plane (001), and a second peak at $2 \theta=25^{\circ}$, corresponding to the plane (002). The weaker and broader peak for (002) suggests that GO is partially reduced [54]. For $\mathrm{N}-\mathrm{GO}$, the peak around $2 \theta=14^{\circ}$ decreased; conversely, the peak at $2 \theta=25^{\circ}$ increased, indicating that the amine functionalization process caused a significant reduction of $\mathrm{GO}$, as reported by Irani et al. [43]. This reduction may be related with the higher thermal stability of N-GO as seen in the TGA results. Cl-GO presented a very weak peak at $2 \theta=25^{\circ}$; thus, the introduction of chlorine may have caused further exfoliation/oxidation of GO, which may have reduced the thermal stability of this material. The results obtained by XRD suggest the successful introduction of functional groups in GO.

The film obtained after the ex situ IP reaction was analyzed using FTIR spectroscopy to study the possible interactions of functionalized GO in the polyamide layer. The results in Figure 1f show that, for the control reaction, there were two peaks at 1715 (I) and $1680 \mathrm{~cm}^{-1}$ (II), corresponding to the carbonyl group from carboxyl acid and the amide groups, respectively. When the reaction was performed using only N-GO as the aminecontaining monomer, the peak at $1680 \mathrm{~cm}^{-1}$ was slightly shifted to $1690 \mathrm{~cm}^{-1}$, indicating that the nature of the amide bond is different from that on the PIP/TMC film. The upshifting of the amide signal for TMC/N-GO could be attributed to the formation of a secondary amide or to the presence of amide groups at the solid (i.e., GO nanosheets). It is of note that this signal at $1690 \mathrm{~cm}^{-1}$ was not observed in the FTIR spectrum of N-GO; therefore, this signal may come from another source. In the case of the reaction between PIP and $\mathrm{Cl}-\mathrm{GO}$ as the acyl chloride-containing reactant, both signals (I and II) presented an increase in the wavenumber, which may be because the carboxylic acid and amide groups were at the surface of the GO, which is a more stiff structure.

\subsection{Morphology Imaging and EDS Characteristics of Functionalized GO}

Figure 2 shows the morphology of the prepared GO. SEM characterization showed that N-GO (Figure 2b) and Cl-GO (Figure 2c) present thinner nanosheets, albeit similar in length, compared to the GO (Figure 2a). Micrographs indicate that functionalization occurred at a molecular level and did not affect the overall structure of the GO. In addition, 
the surface appeared to be smoother for N-GO and Cl-GO than for the pristine GO. This may be because those materials underwent additional steps through synthesis.

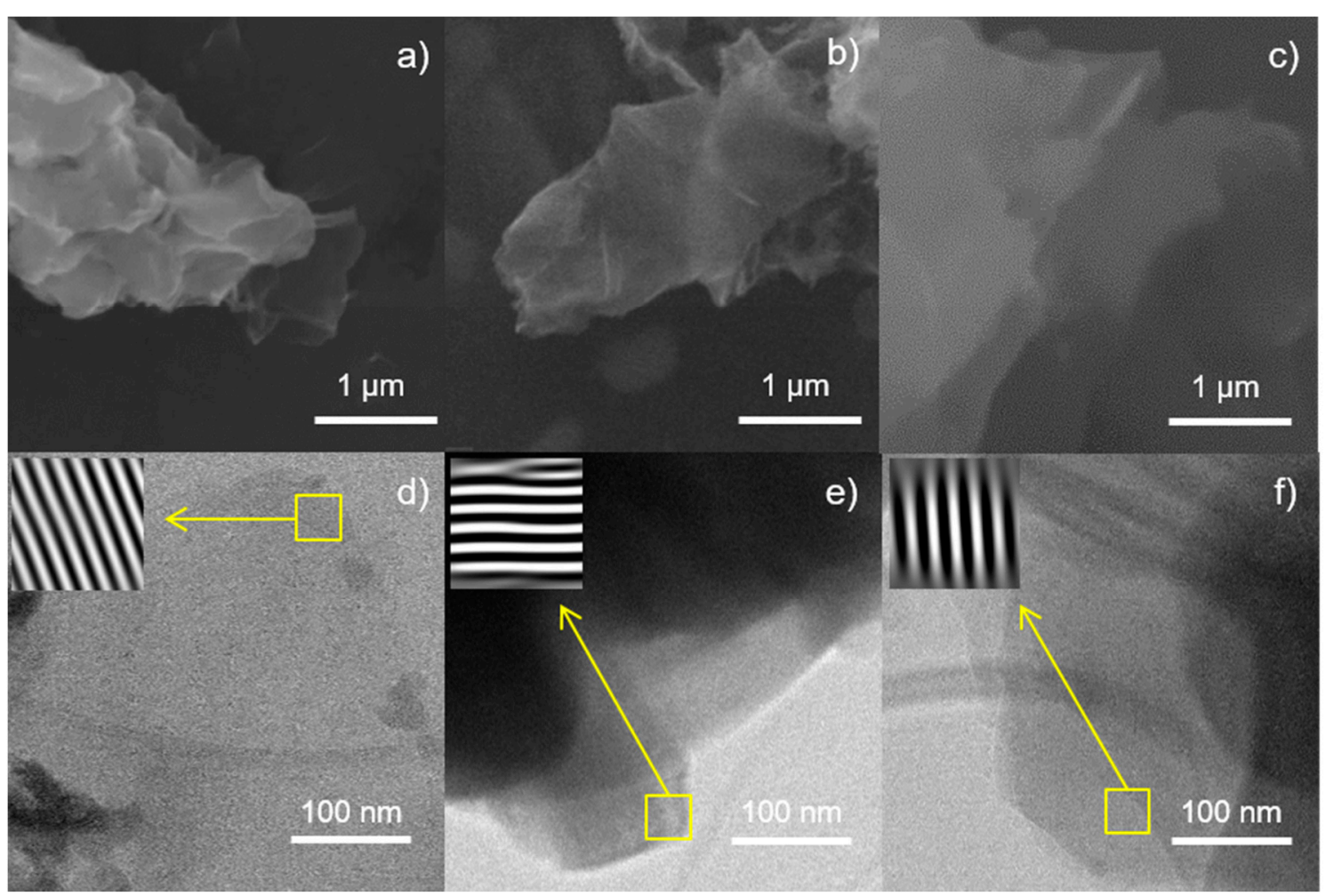

Figure 2. Morphological characterization of synthesized GO. SEM imaging of (a) GO, (b) N-GO, and (c) Cl-GO. TEM bright field imaging of (d) GO, (e) N-GO, and (f) Cl-GO. Inset: magnification of GO layers obtained by FFT processing.

Synthesized materials were characterized by TEM to elucidate the effect of functionalizing in GO structure. Introduction of heteroatoms through functionalization with $\mathrm{N}$ - and $\mathrm{Cl}$-containing groups, may have caused an increase in the interlayer distance ( $d$-spacing). Pristine GO (Figure 2d) showed a $d$-spacing of $0.79 \mathrm{~nm}$, while those of N-GO (Figure 2e) and $\mathrm{Cl}-\mathrm{GO}$ (Figure 2f) increased to 0.82 and $0.83 \mathrm{~nm}$, respectively. This lattice distortion suggests that GO was successfully functionalized.

Elemental analysis shows the atomic composition of the prepared nanomaterials (Table 3), confirming the presence of oxygen in GO. N-GO presented a significant increase in the nitrogen atomic ratio, while the chlorine content also increased for $\mathrm{Cl}-\mathrm{GO}$. This evidence could indicate that both nitrogen and chlorine were introduced in the GO structure.

Table 3. Atomic composition of prepared GO obtained by EDS analysis.

\begin{tabular}{ccccc}
\hline Sample & $\mathbf{C}$ & $\mathbf{O}$ & $\mathbf{N}$ & $\mathbf{C l}$ \\
\hline $\mathrm{GO}$ & $54 \%$ & $43 \%$ & $4 \%$ & $0 \%$ \\
\hline $\mathrm{N}-\mathrm{GO}$ & $57 \%$ & $19 \%$ & $23 \%$ & $1 \%$ \\
\hline $\mathrm{Cl}-\mathrm{GO}$ & $70 \%$ & $6 \%$ & $8 \%$ & $16 \%$ \\
\hline
\end{tabular}

\subsection{Characterization of GO/PA Nanocomposite Membranes}

\subsubsection{FTIR Spectra of Prepared Membranes}

In order to confirm the incorporation of nanomaterials in the PA layer, the FTIR spectra of the prepared membranes were obtained (Figure 3). As a reference, the spectrum of the PSf support was taken. It is clear that most of the signals in the spectra of NF membranes come from the PSf support. The peaks at $1584 \mathrm{~cm}^{-1}, 1485 \mathrm{~cm}^{-1}, 1220 \mathrm{~cm}^{-1}$, and $1120 \mathrm{~cm}^{-1}$ 
correspond to the PSf substrate [55]. The intensity of these signals is lower for the NF membranes since, in these membranes, a PA film covers the PSf. Main differences between NF membranes and PSf are the signals at $1709 \mathrm{~cm}^{-1}$ and $1620 \mathrm{~cm}^{-1}$. The characteristic peak of the amide $\mathrm{I}(\mathrm{C}=\mathrm{O})$ stretch at $1620 \mathrm{~cm}^{-1}$ appears stronger in membranes NF1, NF2, and NF3 than in membranes NF4, NF5, and NF6 [56]. In addition, the membranes prepared incorporating $\mathrm{GO}$ in the organic phase show a stronger carboxylic acid $\mathrm{C}=\mathrm{O}$ signal at $1709 \mathrm{~cm}^{-1}$, indicating the presence of a higher amount of hydrolyzed acyl chloride groups due to solid disaggregation. These results may also be attributed to additional $\mathrm{COOH}$ and $\mathrm{COCl}$ groups in the $\mathrm{GO}$ and $\mathrm{Cl}-\mathrm{GO}$, respectively, added during the preparation of membranes with incorporated GO-based material in the organic phase. NF3 shows a weaker carboxylic $\mathrm{C}=\mathrm{O}$ peak $\left(1709 \mathrm{~cm}^{-1}\right)$ than the membrane NF2, which could be related to the less carboxylic groups in N-GO. A stronger amide $\mathrm{C}=\mathrm{O}$ peak $\left(1620 \mathrm{~cm}^{-1}\right)$ can be observed in NF3 compared to NF2, indicating the presence of amine groups in N-GO. Both NF1 (blank) and NF3 showed similar behavior for $\mathrm{C}=\mathrm{O}\left(1620 \mathrm{~cm}^{-1}\right)$ peak intensity, indicating that the addition of N-GO may have enhanced crosslinking, either by preventing disaggregation of the solid or by forming covalent interactions with PA chains.

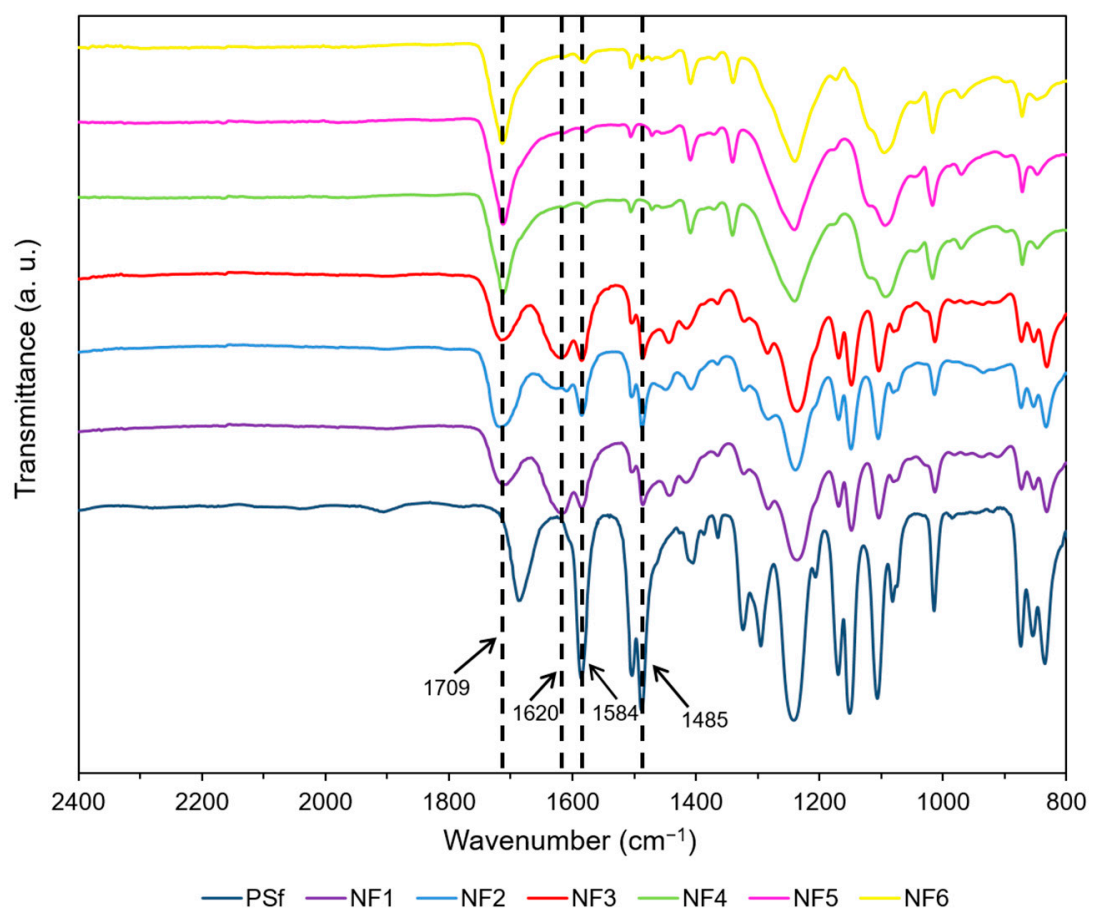

Figure 3. FTIR spectra of prepared membranes.

\subsubsection{SEM Imaging of GO/PA NF Membranes}

Micrographs obtained by SEM are depicted in Figure 4. NF1 (Figure 4a) shows a very smooth surface, while NF2 (Figure 4 b) presents a wrinkled morphology, indicating that GO may have caused the PA layer to become uneven in the latter membrane. A uniform particle distribution with small nodules can be observed in the surface of NF3 (Figure 4c); these agglomerates have diameters smaller than $100 \mathrm{~nm}$. This suggests that the functionalization of GO with amine groups may enhance the degree of crosslinking. In membranes NF4 (Figure 4d) and NF5 (Figure 4e), a granular morphology can be observed, indicating that only some scattered PA chains formed. The presence of the higher-density PA around the Cl-GO particles, as depicted in Figure 4f, may suggest that the GO was successfully functionalized. Figure 5 shows cross-sectional images of the membranes, showing the structure of the porous PSf support and confirming the formation of a top dense-film layer of PA. The blank membrane (NF1) showed a dense layer measuring $218 \pm 5 \mathrm{~nm}$ in thickness, and for NF2, this was $177 \pm 3 \mathrm{~nm}$. This structural change in the membrane 
surface may indicate that, in NF2, IP may have proceeded mostly around GO nanoparticles. However, N-GO-doped membranes presented an increase in film thickness, indicating that this nanomaterial may have participated in IP. It is important to highlight that, during the preparation of the organic phase for NF4, a non-homogeneous dispersion was observed, implying that, during the preparation of this membrane, some agglomerates of GO were formed on the membrane surface. In addition, SEM imaging suggests the formation of a thicker (254 $\pm 7 \mathrm{~nm}$ ) and smoother PA layer. In this case, GO may only have played a role as a scaffold for the formation of polymer chains. Due to an improvement in dispersability, Cl-GO promoted the formation of a thinner layer $(197 \pm 3 \mathrm{~nm})$.

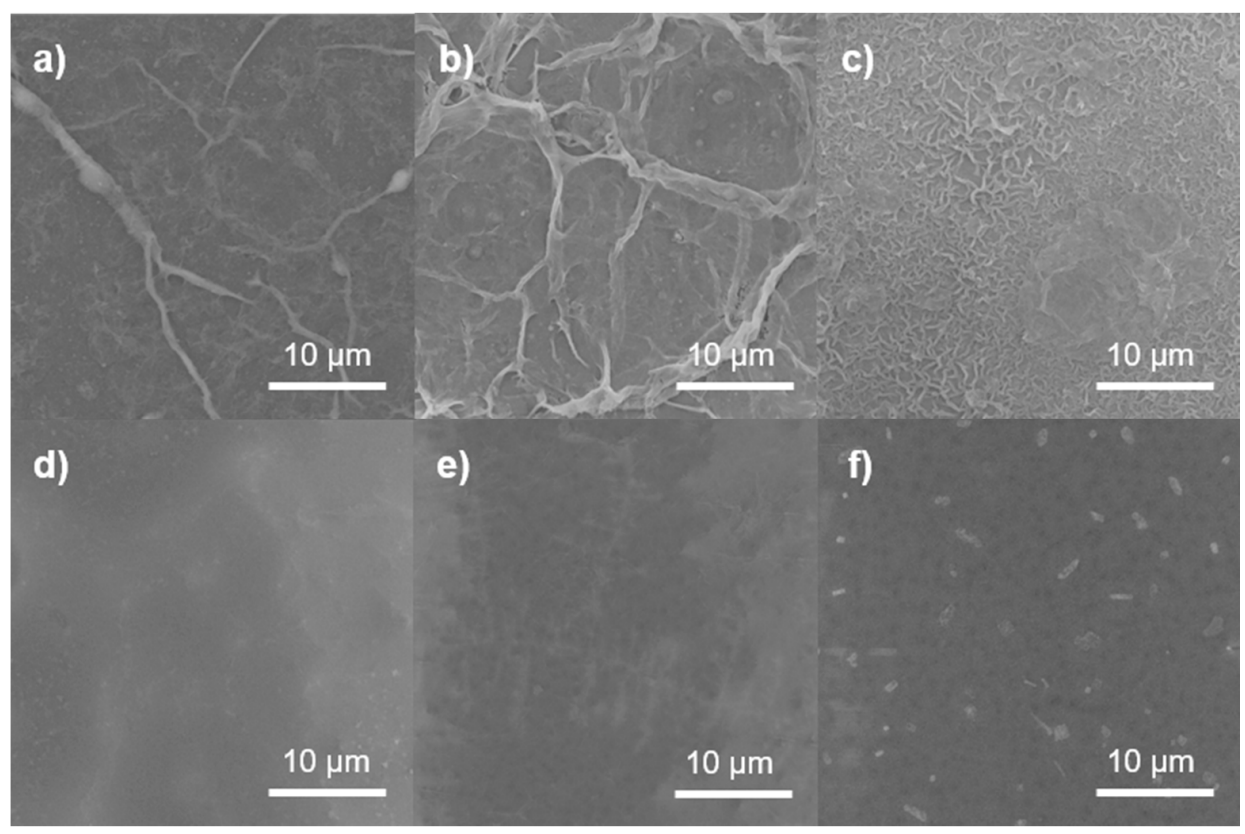

Figure 4. SEM images of NF membranes: (a) NF1, (b) NF2, (c) NF3, (d) NF4, (e) NF5, and (f) NF6.

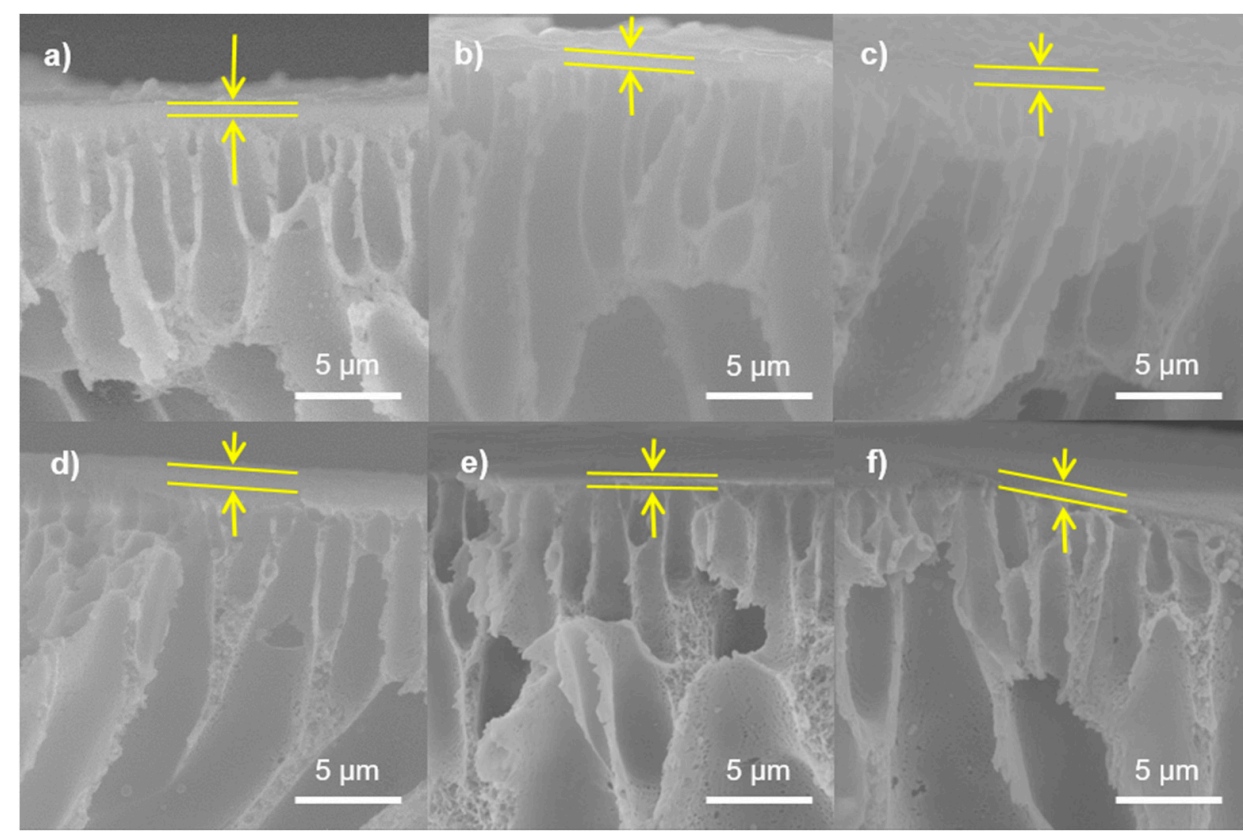

Figure 5. Cross-sectional images obtained by SEM for prepared NF membranes: (a) NF1, (b) NF2, (c) NF3, (d) NF4, (e) NF5, and (f) NF6. 


\subsubsection{AFM Imaging of GO/PA NF Membranes}

For atomic force microscopy characterization, a $25 \mu \mathrm{m}$ window was analyzed. The resulting micrographs (Figure 6) revealed that membrane surface roughness (SR) increased when pristine GO was added, due to the formation of aggregates in the aqueous phase. This is consistent with previous reports by Sirinupong et al. [57]. Comparing the addition of GO (Figure 6b) and that of N-GO (Figure 6c), it is shown that N-GO can reduce membrane surface roughness from 195.5 to $159.3 \mathrm{~nm}$, as this material is more stable when dispersing into the aqueous phase, avoiding lump formation. AFM showed a higher peak-to-peak distance for the membrane NF4 (Figure 6d), which could be attributed to the low stability of GO in iso-octane. The addition of $\mathrm{Cl}-\mathrm{GO}$ also increased membrane surface roughness to $181.3 \mathrm{~nm}$ (Figure 6e). Since Cl-GO was uniformly dispersed in the organic phase, the increase in surface roughness could be attributed to a thicker PA layer. Surprisingly, NF6 (Figure 6f) exhibited a topography similar to that of the blank membrane (NF1), suggesting that, because of the lower amount added to both aqueous and organic phases, most of the functionalized GO could be located at the interface during IP and thus be embedded at the center of the PA layer. This behavior may indicate that functionalized GO is attracted to the interface due to the reacting functional groups on its structure.
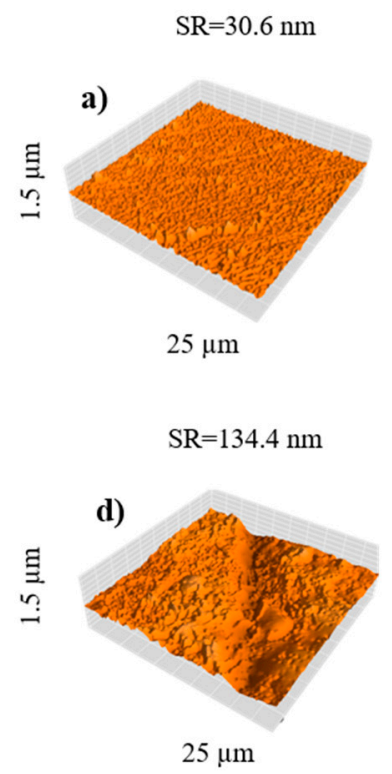

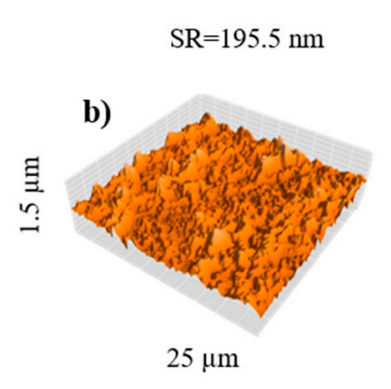

$\mathrm{SR}=181.3 \mathrm{~nm}$

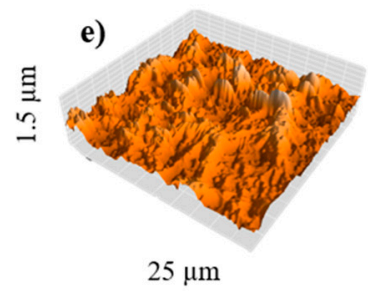

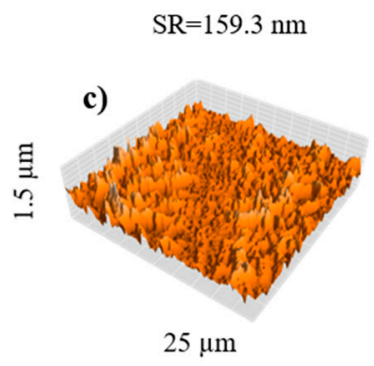

$\mathrm{SR}=30.2 \mathrm{~nm}$

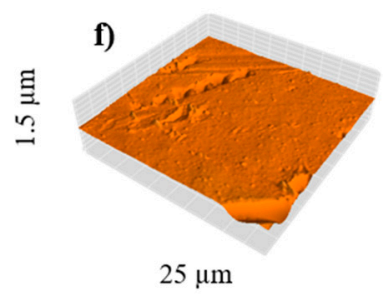

Figure 6. Surface topography of NF membranes: (a) NF1, (b) NF2, (c) NF3, (d) NF4, (e) NF5, and (f) NF6.

\subsection{Performance of NF Membranes}

\subsubsection{Water Flux Test}

All performance tests were carried out in the same chronological order to ensure reliable results. Pure water flux results are shown in Figure 7. Permeance increased from 1.120 to $1.929 \mathrm{~L} \mathrm{~m}^{-2} \mathrm{bar}^{-1} \mathrm{~h}^{-1}$ due to the addition of GO during IP. It is likely that GO disrupted the polymer chains, increasing both pore size and hydrophilicity of the membrane surface. A similar behavior was observed for N-GO. Although N-GO presented less functional groups than GO, a slight increase in permeance for NF3 was observed, compared to NF1. This effect may suggest that fewer groups in N-GO confer high hydrophilicity. Membranes prepared with GO-based materials in the organic phase showed significantly less permeance (up to $35 \%$ lower compared to NF2); this may be related to the SEM and AFM results, which suggest the presence of a thicker selective layer in NF4 and NF5. On the other hand, NF6 reached almost the same permeance value as NF2, while it exhibited a lower surface roughness than the blank membrane. 


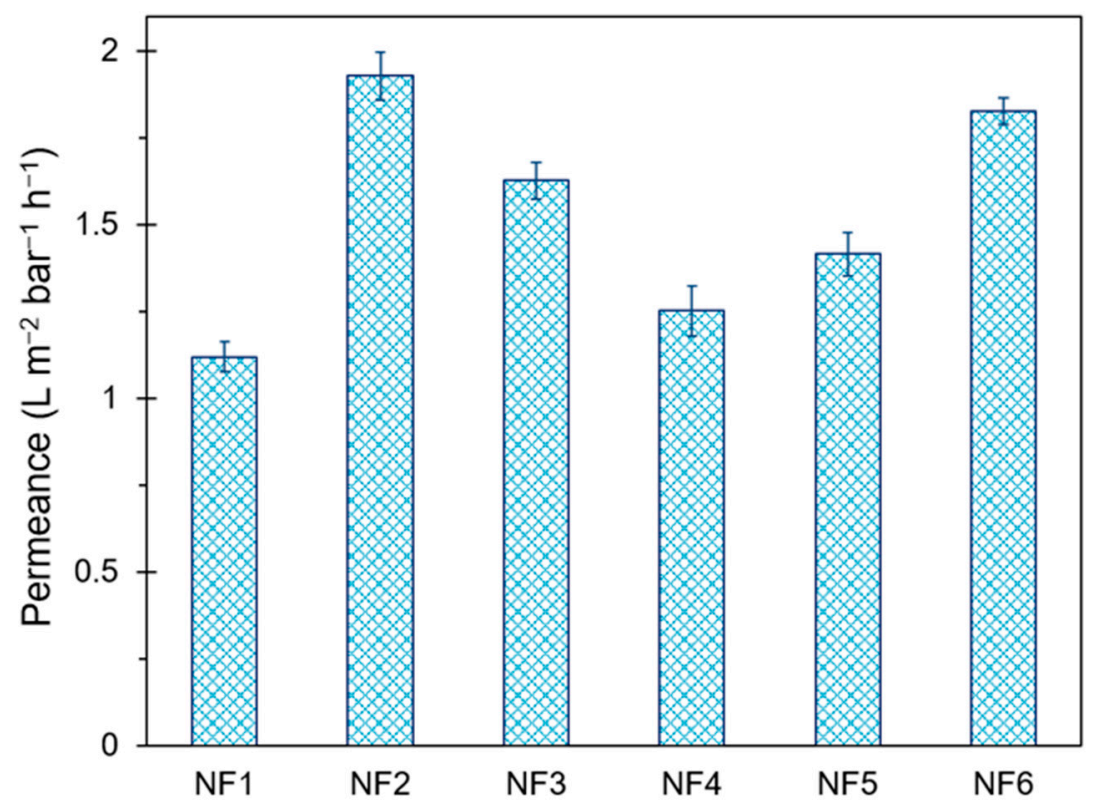

Figure 7. Permeance results in pure water tests for as-prepared membranes.

\subsubsection{Salt Rejection Capacity}

Results from salt rejection tests are presented in Figure 8. All membranes showed a low $\mathrm{NaCl}$ rejection capacity, although the membrane NF5 presented the highest rejection $(67.8 \%)$ for this salt. The membrane NF4 presented the lowest salt rejection and the lowest permeance. This behavior is related to the uneven distribution of the film due to the low dispersability of GO during preparation, as discussed in the SEM section. The formation of these agglomerates may have reduced the filtration effective area for this membrane. Aqueous phase-modified membranes exhibited an increase in $\mathrm{Na}_{2} \mathrm{SO}_{4}$ rejection up to $3 \%$ compared to non-modified membrane. $\mathrm{Cl}-\mathrm{GO}$ membranes presented the highest $\mathrm{Na}_{2} \mathrm{SO}_{4}$ rejection (up to $99.4 \%$ for NF5) at the expense of a lower permeance. This trade-off behavior between water flux and salt rejection is usual in NF membranes [58].

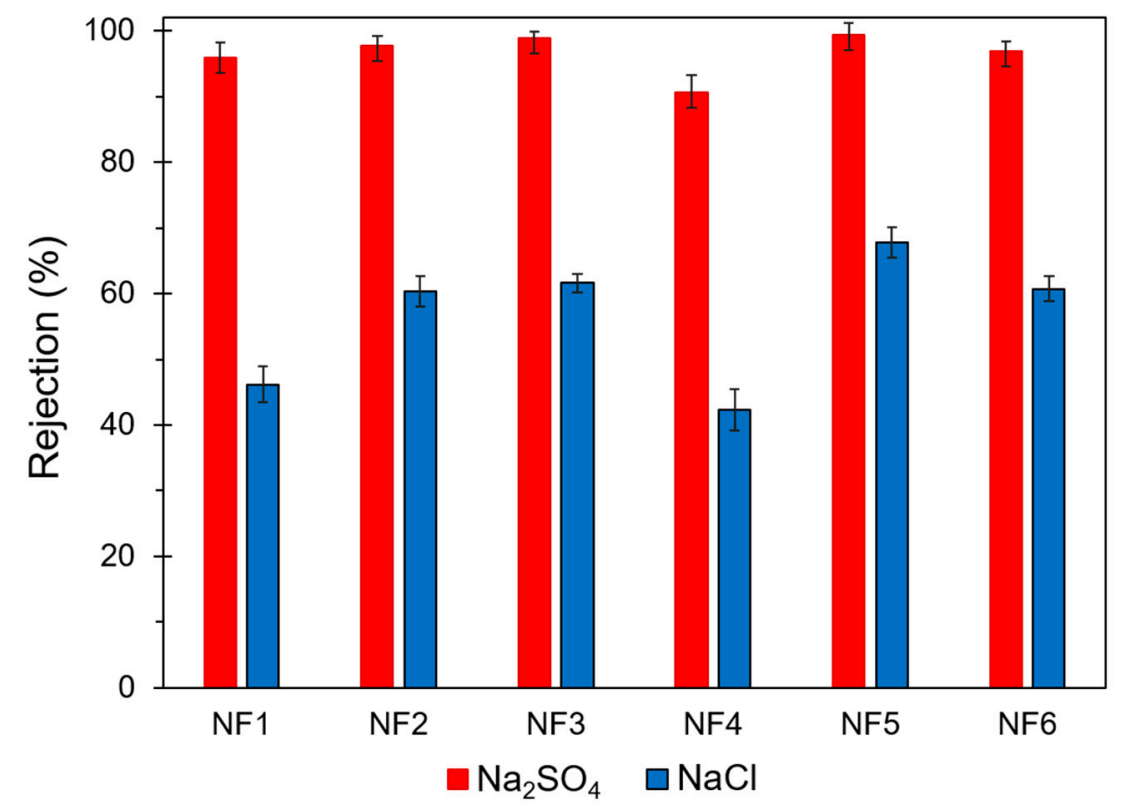

Figure 8. $\mathrm{Na}_{2} \mathrm{SO}_{4}$ and $\mathrm{NaCl}$ rejection capacity of prepared NF membranes. 


\subsubsection{Molecular Weight Cut-Off Determination}

The MWCO for the different membranes was determined by interpolation using Equation (5). The plot of Equation (5) is shown in Figure 9. Results showed that aqueous phasemodified membranes presented lower saccharide rejection, compared to organicphasemodified membranes. This behavior may be caused by a thinner and more porous PA layer in the aqueous phase-modified membranes. The blank membrane presented the highest MWCO (264 g mol$\left.{ }^{-1}\right)$. The NF2 and NF3 membranes achieved outstanding salt rejection without a significant reduction of neutral solute rejection capacity, as they presented an MWCO of 221 and $212 \mathrm{~g} \mathrm{~mol}^{-1}$, respectively. This behavior may indicate that the separation mechanism for NF2 and NF3 is governed by electrostatic interactions rather than by solute size. A higher saccharide retention $\left(\mathrm{MWCO}<203 \mathrm{~g} \mathrm{~mol}^{-1}\right)$ for organic phasemodified membranes suggests the presence of a denser PA layer. This shows agreement with previous results obtained by microscopy.

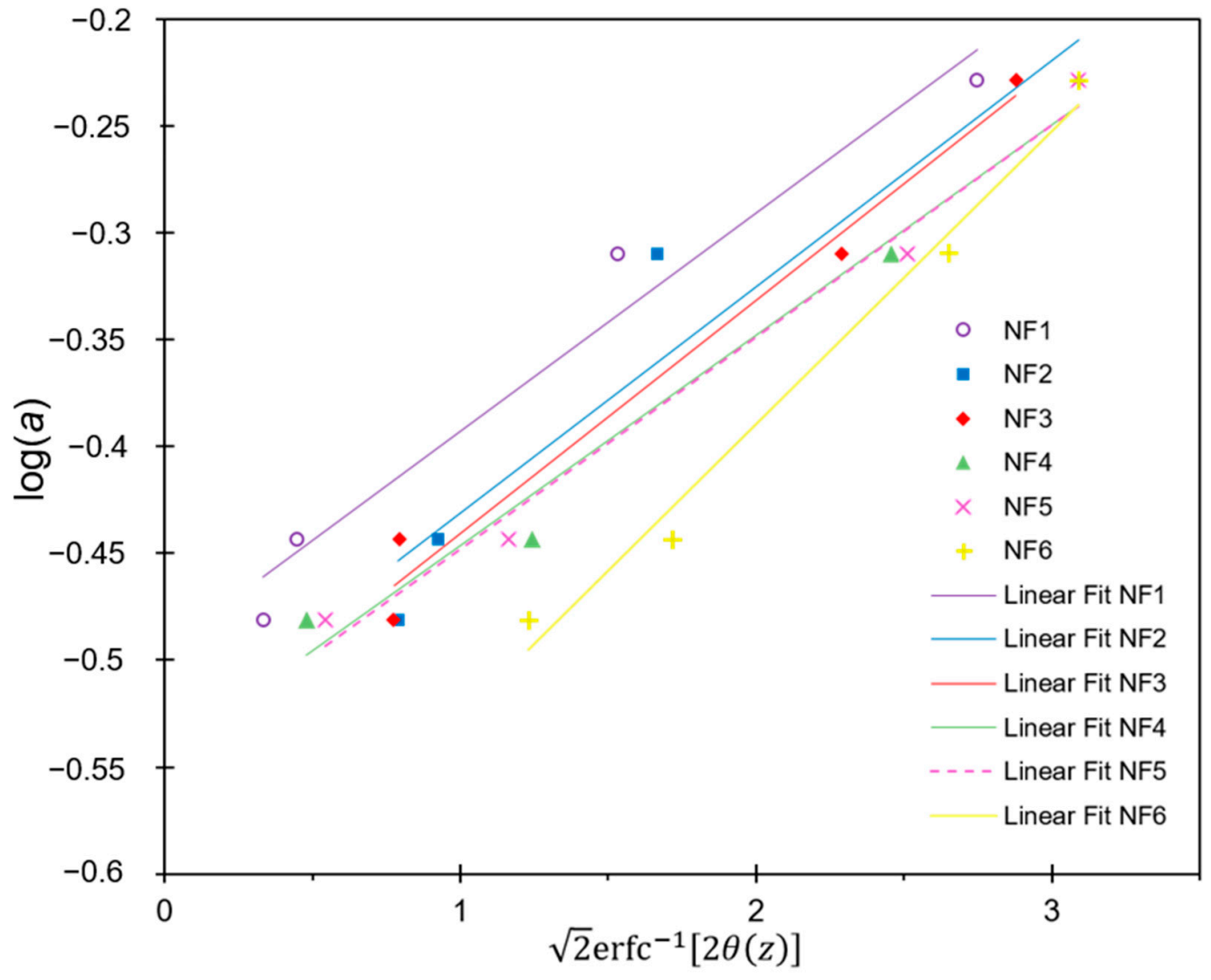

Figure 9. Plot of $\log (a)$ vs $\sqrt{2} \operatorname{erfc}^{-1}[2 \theta(z)]$ for the prepared NF membranes.

Table 4 presents a summary of the most important characteristics of the prepared NF membranes.

Table 4. Summary of results for the PA nanocomposite membranes.

\begin{tabular}{cccccc}
\hline Membrane & $\begin{array}{c}\text { Permeance } \\
\left(\mathbf{L ~ m}^{-\mathbf{2}} \mathbf{b a r}^{-\mathbf{1}} \mathbf{h}^{-\mathbf{1}} \mathbf{)}\right.\end{array}$ & $\begin{array}{c}\text { Rejection for } \\
\mathbf{N a}_{\mathbf{2}} \mathbf{S O} \mathbf{4} \mathbf{( \% )}\end{array}$ & $\begin{array}{c}\text { Rejection for } \\
\mathbf{N a C l} \mathbf{( \% )}\end{array}$ & $\begin{array}{c}\text { MWCO } \\
\left(\mathbf{g ~ m o l}^{-\mathbf{1}} \mathbf{)}\right.\end{array}$ & $\begin{array}{c}\text { Surface } \\
\text { Roughness (nm) }\end{array}$ \\
\hline NF1 & $1.12 \pm 0.04$ & $95.9 \pm 2.3$ & $46.2 \pm 2.7$ & $264 \pm 5$ & $30.6 \pm 0.6$ \\
\hline NF2 & $1.93 \pm 0.07$ & $97.7 \pm 1.6$ & $60.3 \pm 2.3$ & $221 \pm 8$ & $195.5 \pm 3.9$ \\
\hline NF3 & $1.63 \pm 0.05$ & $98.9 \pm 1.1$ & $61.6 \pm 1.4$ & $212 \pm 7$ & $159.3 \pm 3.2$ \\
\hline NF4 & $1.25 \pm 0.07$ & $90.7 \pm 2.6$ & $42.3 \pm 3.1$ & $203 \pm 6$ & $134.4 \pm 2.7$ \\
\hline NF5 & $1.42 \pm 0.06$ & $99.4 \pm 1.8$ & $67.8 \pm 2.3$ & $202 \pm 8$ & $181.3 \pm 3.6$ \\
\hline NF6 & $1.83 \pm 0.04$ & $96.9 \pm 1.5$ & $60.7 \pm 1.9$ & $145 \pm 7$ & $30.2 \pm 0.6$ \\
\hline
\end{tabular}




\section{Conclusions}

A simple method for preparing $\mathrm{N}$ - and $\mathrm{Cl}$-functionalized GO was accomplished with a high degree of functionalization ( $15 \%$ and $\sim 16 \%$ for $\mathrm{N}$ and $\mathrm{Cl}$, respectively). The dispersability of GO in the organic phase was significantly improved due to the incorporation of $\mathrm{COCl}$ groups. The developed ex situ IP reaction proved that it is possible for N-GO and $\mathrm{Cl}-\mathrm{GO}$ to form amide bonds as expected for PIP and TMC, as confirmed by FTIR. The NF membranes prepared adding GO-based materials in the aqueous phase showed remarkable performance for $\mathrm{Na}_{2} \mathrm{SO}_{4}$ separation, with very similar permeance in comparison to other reported NF, which is evidenced in Figure 10 [37,41,46,59,60]; thereby, further applications for water desalination are feasible. On the other hand, prepared Cl-GO/PA membranes presented significantly less permeance but a higher salt rejection capacity. Cl-GO-added membranes showed an increase in saccharide rejection capacity, making other potential applications such as dye or volatile organic compound removal possible. The enhanced dispersability of functionalized GO materials allows for a more uniform distribution of GO in the PA layer, modifying membrane properties. The incorporation of chemically modified GO in the structure of NF membranes appears to be a suitable strategy for improving its permeance.

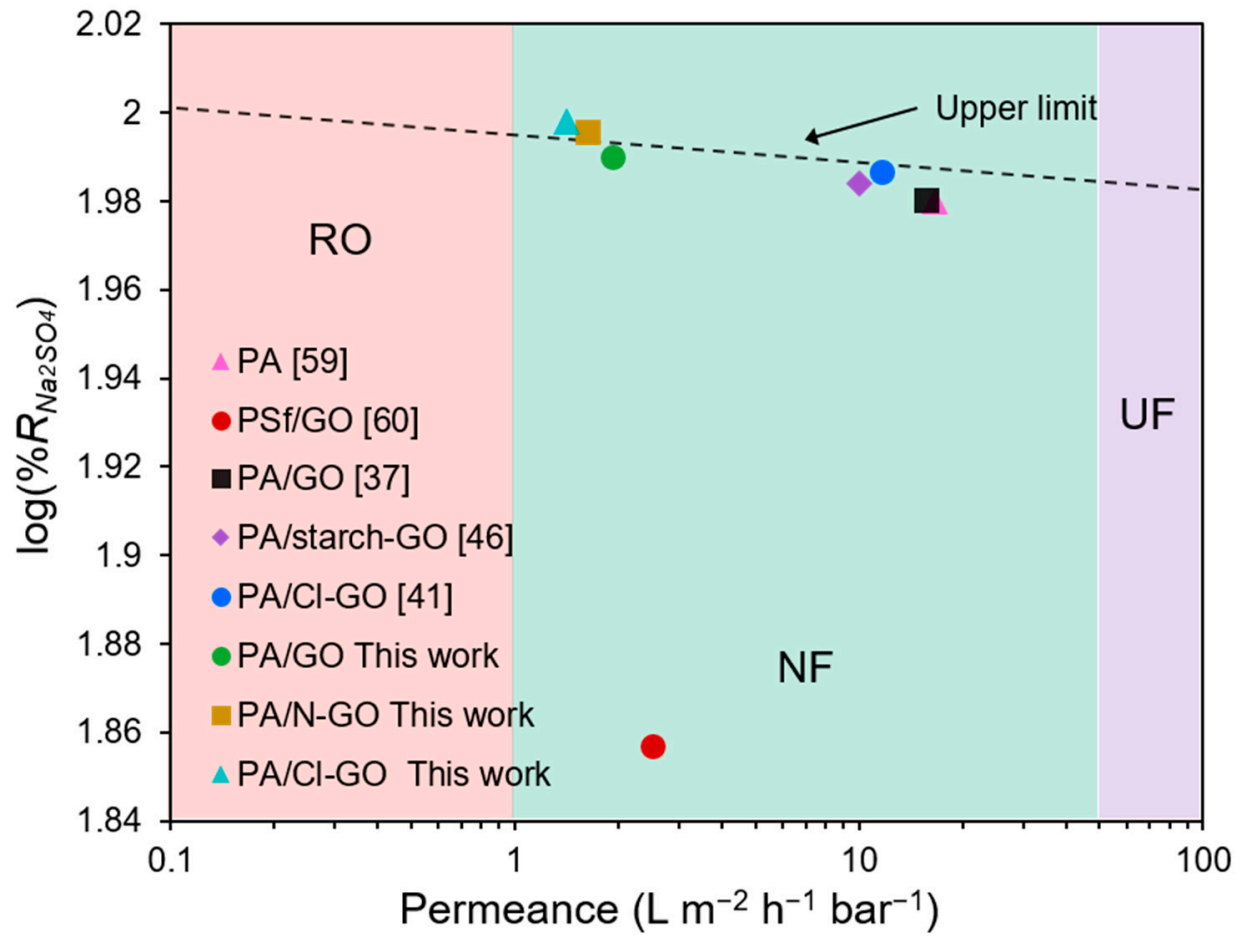

Figure 10. Correlation of permeance and observed $\mathrm{Na}_{2} \mathrm{SO}_{4}$ rejection for similar NF membranes.

Author Contributions: Conceptualization, F.J.G.-P., G.A.F.-W., S.W.L. and S.P.-S.; methodology, F.J.G.-P. and S.P.-S.; software, F.J.G.-P.; formal analysis, M.I.S.-G., B.T.-N. and S.P.-S.; writingoriginal draft preparation, F.J.G.-P.; writing—review and editing, F.J.G.-P., G.A.F.-W., M.I.S.-G., B.T.-N. and S.P.-S.; supervision, S.P.-S.; funding acquisition, S.P.-S. All authors have read and agreed to the published version of the manuscript.

Funding: This research was founded by Tecnológico Nacional de México/Instituto Tecnológico de Tijuana grant no. 6046.19-P.

Institutional Review Board Statement: Not applicable.

Informed Consent Statement: Not applicable. 
Data Availability Statement: The data presented in this study are available on request from the corresponding author.

Acknowledgments: The authors acknowledge Tecnológico Nacional de México/Instituto Tecnológico de Tijuana for providing material and equipment, David Dominguez for XPS analysis, and Francisco Paraguay for TEM characterization. F.J.G.-P. also thanks CONACYT for supporting the scholarship for postgraduate studies.

Conflicts of Interest: The authors declare no conflict of interest.

\section{References}

1. WHO. Health Topics: Water Fact Sheet. 2018. Available online: https://www.who.int/news-room/fact-sheets/detail/drinkingwater (accessed on 6 March 2020).

2. Baker, R.W. Membrane Technology and Applications, 2nd ed.; John Wiley \& Sons: Chichester, UK, 2012; p. 575. [CrossRef]

3. Homayoonfal, M.; Akbari, A.; Mehrnia, M.R. Preparation of polysulfone nanofiltration membranes by UV-assisted grafting polymerization for water softening. Desalination 2010, 263, 217-225. [CrossRef]

4. Huang, J.; Zhang, K. The high flux poly (m-phenylene isophthalamide) nanofiltration membrane for dye purification and desalination. Desalination 2011, 282, 19-26. [CrossRef]

5. Zhu, Y.; Dou, P.; He, H.; Lan, H.; Xu, S.; Zhang, Y.; He, T.; Niu, J. Improvement of permeability and rejection of an acid resistant polysulfonamide thin-film composite nanofiltration membrane by a sulfonated poly (ether ether ketone) interlayer. Sep. Purif. Technol. 2020, 239, 116528. [CrossRef]

6. Guo, Y.-S.; Ji, Y.-L.; Wu, B.; Wang, N.-X.; Yin, M.-J.; An, Q.-F.; Gao, C.-J. High-flux zwitterionic nanofiltration membrane constructed by in-situ introduction method for monovalent salt/antibiotics separation. J. Membr. Sci. 2020, 593, 117441. [CrossRef]

7. Wang, J.; He, R.; Han, X.; Jiao, D.; Zhu, J.; Lai, F.; Liu, X.; Liu, J.; Zhang, Y.; Van Der Bruggen, B. High performance loose nanofiltration membranes obtained by a catechol-based route for efficient dye/salt separation. Chem. Eng. J. 2019, 375, 121982. [CrossRef]

8. Gu, J.-E.; Jun, B.-M.; Kwon, Y.-N. Effect of chlorination condition and permeability of chlorine species on the chlorination of a polyamide membrane. Water Res. 2012, 46, 5389-5400. [CrossRef]

9. Haghighat, N.; Vatanpour, V. Fouling decline and retention increase of polyvinyl chloride nanofiltration membranes blended by polypyrrole functionalized multiwalled carbon nanotubes. Mater. Today Commun. 2020, 23, 100851. [CrossRef]

10. Jye, L.W.; Ismail, A.F. Nanofiltration Membranes: Synthesis, Characterization, and Applications; CRC Press: Boca Raton, FL, USA, 2016.

11. Lee, K.P.; Arnot, T.C.; Mattia, D. A review of reverse osmosis membrane materials for desalination-Development to date and future potential. J. Membr. Sci. 2011, 370, 1-22. [CrossRef]

12. Hai, Y.; Zhang, J.; Shi, C.; Zhou, A.; Bian, C.; Li, W. Thin film composite nanofiltration membrane prepared by the interfacial polymerization of 1,2,4,5-benzene tetracarbonyl chloride on the mixed amines cross-linked poly (ether imide) support. J. Membr. Sci. 2016, 520, 19-28. [CrossRef]

13. Morales-Cuevas, J.B.; Pérez-Sicairos, S.; Lin, S.W.; Salazar-Gastélum, M.I. Evaluation of a modified spray-applied interfacial polymerization method for preparation of nanofiltration membranes. J. Appl. Polym. Sci. 2019, 136, 1-10. [CrossRef]

14. Esfandian, F.; Peyravi, M.; Ghoreyshi, A.A.; Jahanshahi, M.; Rad, A.S. Fabrication of TFC nanofiltration membranes via co-solvent assisted interfacial polymerization for lactose recovery. Arab. J. Chem. 2019, 12, 5325-5338. [CrossRef]

15. Echaide-Górriz, C.; Zapata, J.A.; Etxeberría-Benavides, M.; Téllez, C.; Coronas, J. Polyamide/MOF bilayered thin film composite hollow fiber membranes with tuned MOF thickness for water nanofiltration. Sep. Purif. Technol. 2020, 236, 116265. [CrossRef]

16. Arumugham, T.; Kaleekkal, N.J.; Rana, D. Fabrication of novel aromatic amine functionalized nanofiltration (NF) membranes and testing its dye removal and desalting ability. Polym. Test. 2018, 72, 1-10. [CrossRef]

17. Huang, Y.; Sun, J.; Wu, D.; Feng, X. Layer-by-layer self-assembled chitosan/PAA nanofiltration membranes. Sep. Purif. Technol. 2018, 207, 142-150. [CrossRef]

18. Guo, D.; Xiao, Y.; Li, T.; Zhou, Q.; Shen, L.; Li, R.; Xu, Y.; Lin, H. Fabrication of high-performance composite nanofiltration membranes for dye wastewater treatment: Mussel-inspired layer-by-layer self-assembly. J. Colloid Interface Sci. 2020, 560, 273-283. [CrossRef]

19. Ben-Sasson, M.; Lu, X.; Bar-Zeev, E.; Zodrow, K.R.; Nejati, S.; Qi, G.; Giannelis, E.P.; Elimelech, M. In situ formation of silver nanoparticles on thin-film composite reverse osmosis membranes for biofouling mitigation. Water Res. 2014, 62, 260-270. [CrossRef]

20. Abadikhah, H.; Kalali, E.N.; Behzadi, S.; Khan, S.A.; Xu, X.; Shabestari, M.E.; Agathopoulos, S. High flux thin film nanocomposite membrane incorporated with functionalizedTiO2@reduced graphene oxide nanohybrids for organic solvent nanofiltration. Chem. Eng. Sci. 2019, 204, 99-109. [CrossRef]

21. Li, Y.-X.; Cao, Y.; Wang, M.; Xu, Z.-L.; Zhang, H.-Z.; Liu, X.-W.; Li, Z. Novel high-flux polyamide/TiO2 composite nanofiltration membranes on ceramic hollow fibre substrates. J. Membr. Sci. 2018, 565, 322-330. [CrossRef]

22. Low, Z.-X.; Wang, Z.; Leong, S.; Razmjou, A.; Dumée, L.F.; Zhang, X.; Wang, H. Enhancement of the Antifouling Properties and Filtration Performance of Poly(ethersulfone) Ultrafiltration Membranes by Incorporation of Nanoporous Titania Nanoparticles. Ind. Eng. Chem. Res. 2015, 54, 11188-11198. [CrossRef] 
23. Ang, M.B.M.Y.; Trilles, C.A.; De Guzman, M.R.; Pereira, J.M.; Aquino, R.R.; Huang, S.-H.; Hu, C.-C.; Lee, K.-R.; Lai, J.-Y. Improved performance of thin-film nanocomposite nanofiltration membranes as induced by embedded polydopamine-coated silica nanoparticles. Sep. Purif. Technol. 2019, 224, 113-120. [CrossRef]

24. Beisl, S.; Monteiro, S.; Santos, R.; Figueiredo, A.S.; Sánchez-Loredo, M.G.; Lemos, M.A.; Lemos, F.; Minhalma, M.; de Pinho, M.N. Synthesis and bactericide activity of nanofiltration composite membranes-Cellulose acetate/silver nanoparticles and cellulose acetate/silver ion exchanged zeolites. Water Res. 2019, 149, 225-231. [CrossRef]

25. Al-Hinai, M.H.; Sathe, P.; Al-Abri, M.Z.; Dobretsov, S.; Al-Hinai, A.T.; Dutta, J. Antimicrobial Activity Enhancement of Poly (ether sulfone) Membranes by in Situ Growth of ZnO Nanorods. ACS Omega 2017, 2, 3157-3167. [CrossRef] [PubMed]

26. Xue, S.-M.; Xu, Z.-L.; Tang, Y.-J.; Ji, C.-H. Polypiperazine-amide Nanofiltration Membrane Modified by Different Functionalized Multiwalled Carbon Nanotubes (MWCNTs). ACS Appl. Mater. Interfaces 2016, 8, 19135-19144. [CrossRef]

27. Wu, M.-B.; Lv, Y.; Yang, H.-C.; Liu, L.-F.; Zhang, X.; Xu, Z.-K. Thin film composite membranes combining carbon nanotube intermediate layer and microfiltration support for high nanofiltration performances. J. Membr. Sci. 2016, 515, 238-244. [CrossRef]

28. Zhao, H.; Qiu, S.; Wu, L.; Zhang, L.; Chen, H.; Gao, C. Improving the performance of polyamide reverse osmosis membrane by incorporation of modified multi-walled carbon nanotubes. J. Membr. Sci. 2014, 450, 249-256. [CrossRef]

29. Wang, L.; Song, X.; Wang, T.; Wang, S.; Wang, Z.; Gao, C. Fabrication and characterization of polyethersulfone/carbon nanotubes (PES/CNTs) based mixed matrix membranes (MMMs) for nanofiltration application. Appl. Surf. Sci. 2015, 330, 118-125. [CrossRef]

30. Li, X.; Zhao, C.; Yang, M.; Yang, B.; Hou, D.; Wang, T. Reduced graphene oxide-NH2 modified low pressure nanofiltration composite hollow fiber membranes with improved water flux and antifouling capabilities. Appl. Surf. Sci. 2017, 419, 418-428. [CrossRef]

31. Hu, R.; Zhang, R.; He, Y.; Zhao, G.; Zhu, H. Graphene oxide-in-polymer nanofiltration membranes with enhanced permeability by interfacial polymerization. J. Membr. Sci. 2018, 564, 813-819. [CrossRef]

32. Kang, Y.; Obaid, M.; Jang, J.; Kim, I.S. Sulfonated graphene oxide incorporated thin film nanocomposite nanofiltration membrane to enhance permeation and antifouling properties. Desalination 2019, 470, 114125. [CrossRef]

33. Nam, Y.T.; Kim, S.J.; Kang, K.M.; Jung, W.-B.; Kim, D.W.; Jung, H.-T. Enhanced nanofiltration performance of graphene-based membranes on wrinkled polymer supports. Carbon N. Y. 2019, 148, 370-377. [CrossRef]

34. Hua, D.; Chung, T.-S. Polyelectrolyte functionalized lamellar graphene oxide membranes on polypropylene support for organic solvent nanofiltration. Carbon N. Y. 2017, 122, 604-613. [CrossRef]

35. Anand, A.; Unnikrishnan, B.; Mao, J.-Y.; Lin, H.-J.; Huang, C.-C. Graphene-based nanofiltration membranes for improving salt rejection, water flux and antifouling-A review. Desalination 2018, 429, 119-133. [CrossRef]

36. Muzyka, R.; Kwoka, M.; Smędowski, Ł.; Díez, N.; Gryglewicz, G. Oxidation of graphite by different modified Hummers methods. New Carbon Mater. 2017, 32, 15-20. [CrossRef]

37. Zhao, W.; Liu, H.; Meng, N.; Jian, M.; Wang, H.; Zhang, X. Graphene oxide incorporated thin film nanocomposite membrane at low concentration monomers. J. Membr. Sci. 2018, 565, 380-389. [CrossRef]

38. Lai, G.; Lau, W.; Goh, P.; Tan, Y.; Ng, B.; Ismail, A. A novel interfacial polymerization approach towards synthesis of graphene oxide-incorporated thin film nanocomposite membrane with improved surface properties. Arab. J. Chem. 2019, $12,75-87$. [CrossRef]

39. Chang, Y.; Yang, S.-T.; Liu, J.-H.; Dong, E.; Wang, Y.; Cao, A.; Liu, Y.; Wang, H. In vitro toxicity evaluation of graphene oxide on A549 cells. Toxicol. Lett. 2011, 200, 201-210. [CrossRef] [PubMed]

40. Shao, W.; Liu, C.; Ma, H.; Hong, Z.; Xie, Q.; Lu, Y. Fabrication of pH-sensitive thin-film nanocomposite nanofiltration membranes with enhanced performance by incorporating amine-functionalized graphene oxide. Appl. Surface Sci. 2019, 487, 1209-1221. [CrossRef]

41. Wen, P.; Chen, Y.; Hu, X.; Cheng, B.; Liu, D.; Zhang, Y.; Nair, S. Polyamide thin film composite nanofiltration membrane modified with acyl chlorided graphene oxide. J. Membr. Sci. 2017, 535, 208-220. [CrossRef]

42. Marcano, D.C.; Kosynkin, D.V.; Berlin, J.M.; Sinitskii, A.; Sun, Z.; Slesarev, A.; Alemany, L.B.; Lu, W.; Tour, J.M. Improved Synthesis of Graphene Oxide. ACS Nano 2010, 4, 4806-4814. [CrossRef] [PubMed]

43. Irani, V.; Tavasoli, A.; Vahidi, M. Preparation of amine functionalized reduced graphene oxide/methyl diethanolamine nanofluid and its application for improving the CO2 and H2S absorption. J. Colloid Interface Sci. 2018, 527, 57-67. [CrossRef]

44. Ayala, C.E.; Villalpando, A.; Nguyen, A.L.; McCandless, G.T.; Kartika, R. Chlorination of Aliphatic Primary Alcohols via Triphosgene-Triethylamine Activation. Org. Lett. 2012, 14, 3676-3679. [CrossRef]

45. Lin, S.W.; Martínez-Ayala, A.V.; Pérez-Sicairos, S.; Félix-Navarro, R.M. Preparation and characterization of low-pressure and high MgSO4 rejection thin-film composite NF membranes via interfacial polymerization process. Polym. Bull. 2019, 76, 5619-5632. [CrossRef]

46. Ambre, J.P.; Dhopte, K.B.; Nemade, P.R.; Dalvi, V.H. High flux hyperbranched starch-graphene oxide piperazinamide composite nanofiltration membrane. J. Environ. Chem. Eng. 2019, 7, 103300. [CrossRef]

47. Otero, J.; Mazarrasa, O.; Villasante, J.; Silva, V.; Prádanos, P.; Calvo, J.; Hernández, A. Three independent ways to obtain information on pore size distributions of nanofiltration membranes. J. Membr. Sci. 2008, 309, 17-27. [CrossRef]

48. Cheng, X.Q.; Shao, L.; Lau, C.H. High flux polyethylene glycol based nanofiltration membranes for water environmental remediation. J. Membr. Sci. 2015, 476, 95-104. [CrossRef] 
49. Larkin, P.J. Illustrated and Raman Spectra Demonstrating Important Functional Groups; Elsevier: New York, NY, USA, 2018; pp. 153-210.

50. Long, D.A. Infrared and Raman characteristic group frequencies. Tables and chartsGeorge Socrates John Wiley and Sons, Ltd, Chichester, Third Edition, 2001. Price £135. J. Raman Spectrosc. 2004, 35, 905. [CrossRef]

51. Briggs, D. Handbook of X-ray Photoelectron Spectroscopy C. D. Wanger, W.M. Riggs, L.E. Davis, J.F. Moulder and G. E. Muilenberg Perkin-Elmer Corp., Physical Electronics Division, Eden Prairie, Minnesota, USA, 1979. 190 pp. \$195. Surf. Interface Anal. 1981, 3. [CrossRef]

52. Lai, L.; Chen, L.; Zhan, D.; Sun, L.; Liu, J.; Lim, S.H.; Poh, C.K.; Shen, Z.; Lin, J. One-step synthesis of NH2-graphene from in situ graphene-oxide reduction and its improved electrochemical properties. Carbon N. Y. 2011, 49, 3250-3257. [CrossRef]

53. Latiff, N.M.; Mayorga-Martinez, C.C.; Wang, L.; Sofer, Z.; Fisher, A.C.; Pumera, M. Microwave irradiated N- and B,Cl-doped graphene: Oxidation method has strong influence on capacitive behavior. Appl. Mater. Today 2017, 9, 204-211. [CrossRef]

54. Wang, C.; Li, Z.; Chen, J.; Yin, Y.; Wu, H. Structurally stable graphene oxide-based nanofiltration membranes with bioadhesive polydopamine coating. Appl. Surf. Sci. 2018, 427, 1092-1098. [CrossRef]

55. Ghaemi, N.; Madaeni, S.S.; Alizadeh, A.; Daraei, P.; Badieh, M.M.S.; Falsafi, M.; Vatanpour, V. Fabrication and modification of polysulfone nanofiltration membrane using organic acids: Morphology, characterization and performance in removal of xenobiotics. Sep. Purif. Technol. 2012, 96, 214-228. [CrossRef]

56. Soroush, A.; Barzin, J.; Barikani, M.; Fathizadeh, M. Interfacially polymerized polyamide thin film composite membranes: Preparation, characterization and performance evaluation. Desalination 2012, 287, 310-316. [CrossRef]

57. Sirinupong, T.; Youravong, W.; Tirawat, D.; Lau, W.; Lai, G.; Ismail, A. Synthesis and characterization of thin film composite membranes made of PSF-TiO2/GO nanocomposite substrate for forward osmosis applications. Arab. J. Chem. 2018, 11, 1144-1153. [CrossRef]

58. Geise, G.M.; Park, H.B.; Sagle, A.C.; Freeman, B.D.; McGrath, J.E. Water permeability and water/salt selectivity tradeoff in polymers for desalination. J. Membr. Sci. 2011, 369, 130-138. [CrossRef]

59. Yang, S.; Wang, J.; Fang, L.; Lin, H.; Liu, F.; Tang, C.Y. Electrosprayed polyamide nanofiltration membrane with intercalated structure for controllable structure manipulation and enhanced separation performance. J. Membr. Sci. 2020, 602, 117971. [CrossRef]

60. Ganesh, B.M.; Isloor, A.M.; Ismail, A.F. Enhanced hydrophilicity and salt rejection study of graphene oxide-polysulfone mixed matrix membrane. Desalination 2013, 313, 199-207. [CrossRef] 